\title{
Comparison of Antitumor Activity of Some Benzothiophene and Thienothiophene Carboxanilides and Quinolones in 2D and 3D Cell Culture System
}

\author{
Ivo Zlatar, ${ }^{1, *}$ Dubravko Jelić, ${ }^{1}$ Vanja Kelava, ${ }^{2}$ Maja Cindrić, ${ }^{3}$ Ivana Jarak, ${ }^{4}$ Sanja Koštrun, ${ }^{2}$ Grace Karminski-Zamola, ${ }^{3}$ \\ Vesna Gabelica Marković, ${ }^{2}$ Marijana Hranjec, ${ }^{3}$ Karmen Brajša ${ }^{1}$
}

\footnotetext{
1 Pharmacology in vitro, Fidelta Ltd., Prilaz baruna Filipovića 29, HR-10000 Zagreb, Croatia

2 Chemistry Department, Fidelta Ltd., Prilaz baruna Filipovića 29, HR-10000 Zagreb, Croatia

3 Faculty of Chemical Engineering and Technology, Department of Organic Chemistry, Marulićev trg 20, HR-10000 Zagreb, Croatia

${ }^{4}$ CICECO - Aveiro Institute of Materials, Department of Chemistry, University of Aveiro, 3810-193 Aveiro, Portugal

* Corresponding author's e-mail address: ivo.zlatar@glpg.com
}

RECEIVED: April 10, 2017 * REVISED: April 25, 2017 * ACCEPTED: June 14, 2017

\begin{abstract}
One of the main reasons for the high drug attrition rate in oncology is the poor clinical predictive power of 2D cancer cell lines cultures in vitro which are the standard assay used as screening assay to select new chemical entities (NKE) with potent anticancer activity. Therefore, there is increasing interest in developing 3D in vitro cell culture systems, as a primary screening assays which would represent a biologically more relevant assay system, due to similarity to physiological conditions in which tumors growth in living organism. Very important is to develop reproducible 3D cell line culture in vitro assays, feasible for the primary screening of NKEs platforms. Within this manuscript we have tested small platform of selected benzo[b]thieno, thieno[2,3-b]thiophene, and thieno[3,2-b]thiophene 2-carboxanilides, as well as their cyclic derivatives [2,3-c]quinolones, which already showed anti-proliferative activity on other cancer cell lines in 2D system. Platform was tested in 2D and 3D cancer cell culture assays on three human breast cancer cell lines (SK-BR-3, MDA-MB-231, T-47D). Those cell lines were selected on the basis of ability to growth and form cell spheres and also on different sensitivity to chemotherapeutic agents. We used doxorubicin as control compound due similar mode of action, (specific intercalation with the DNA double helix), as tested compound probably have.

Obtained results in some cases showed significant disagreement, indicating that in early screening selection of active compounds only on 2D activity basis we could pick up false positive compounds (active only on 2D cell culture lines and not on 3D cell lines for which it is clamed that are more similar to real physiological conditions for tumor growth). One possibility for obtained discrepancy of results obtained on 2D and 3D cell cultures could be physico-chemical properties of compounds. Therefore, we analyzed some physico-chemical properties of active compounds as chrom logD values and calculated structural parameters: number of hydrogen bond donors and acceptors, calculated logP and $\log \mathrm{D}$ values, molecular weight, ionization constants (pKa), number of aromatic rings, number of rotatable bonds and polar surface area. Association of physico-chemical descriptors with observed anti-proliferative activity has been investigated. Basicity, molecular weight and number of $\mathrm{H}$-bond donors are found to be main factors contributing to the anti-proliferative effect of investigated compounds for both 2D and $3 \mathrm{D}$ cell cultures.
\end{abstract}

Keywords: antitumor activity, benzothiophenes and carboxanilides, thienothiophenes, quinolones, 2D and 3D in vitro cell assay, lipophilicity.

\section{INTRODUCTION}

A LMOST all cell-based assays within the pharmaceutical drug discovery research use the traditional approach of screening on two dimensional (2D) cell culture models. In 2D culture conditions cells need to adjust to a flat and rigid surface that can result in altered cell metabolism and functionality. ${ }^{[1,2]}$ Thus, cellular functions and physiological responses that are present in organs are often lost in 2D cell cultures which are usual standard for testing new chemical entities (NCE). The ability of an in vitro biological assay to produce reliable information about tested NCEs is essential in early drug development because it is a base of selection of active compounds for further profiling. Loosing cellular and physiological functions in 2D cell cultures influence ability of an in vitro assay to produce 
reliable information about activities of the tested NCE's, which is essential in early phase of drug development. Therefore, there is a continuous need for improvement of existing in vitro technologies, in order to get more accurate and more predictive selection of active compounds based on biological data in pre-clinical screening assays.

Three-dimensional (3D) cell culture techniques have become increasingly popular and are suggested to be better models than two-dimensional monolayers due to improved cell-to-cell contact and structures that resemble in vivo architecture. ${ }^{[3]}$ Cell shape and contacts between cells influence the cytoskeleton which can regulate gene and protein expression and hence cell function. ${ }^{[4,5]}$ Once expensive, laborious and difficult to be used for screening of numerous novel chemical entities, 3D spheroid cultures technique is today applicable for both basic research and high-throughput screening (HTS). Hanging drop method is one of the most well characterised models for 3D culture. In our research we have used 3D Biomatrix hanging drop plates (http://3dbiomatrix.com/) because they support growing of 3D cell culture on a larger scale and also highthroughput screening of NCE. They support production of 3D cell cultures of broad range of different cell lines, and enable produced 3D cultures to be tested in a highthroughput manner. ${ }^{[6]}$ Also, because it is a scaffold free system, they eliminate the possibility of interaction of the NCE with scaffold material.

In a recently published paper we recognized different drug sensitivity properties of some breast and pancreas cancer cell lines, if growing in 2D and 3D conditions. Also, activity of some amidino substituted benzimidazole and benzimidazo[1,2-a]quinoline derivatives tested on $2 \mathrm{D}$ and $3 \mathrm{D}$ cancer cell assay was different. In general, $\mathrm{IC}_{50}$ values from $3 \mathrm{D}$ assay were higher in comparison with $\mathrm{IC}_{50}$ values obtained in $2 \mathrm{D}$ cell model papers. ${ }^{[7]}$ Because the $2 \mathrm{D}$ cancer cell line cultures in vitro are still standard assay used for selection of active compounds with anti-proliferative activity, it is important to compare activity of compounds in 2D and $3 \mathrm{D}$ cell culture systems. Previously obtained significant disagreement in $\mathrm{IC}_{50}$ values for tested compounds indicate that in early screening selection of active compounds only on $2 \mathrm{D}$ activity basis we could pick up false positive compounds which are active only on 2D cell culture lines and not on 3D cell lines for which it is clamed that are more similar to real physiological conditions for tumor growth.

In this paper we analysed physicochemical properties of tested compounds as possible reason for different activity. It was showed that penetration of compounds is more difficult in compounds that growth in spherical way in comparison with cells in monolayer. ${ }^{[8]}$ Also, due to assay validation assay quality parameters ( $Z^{\prime}$ and signal to background, $S: B$ ) for both $2 \mathrm{D}$ and $3 \mathrm{D}$ cell assays were analysed.
Over the past few years substituted nitrogen and sulphur heterocycles have been one of the most extensively studied classes of organic compounds due to their wellknown biological activities and thus, they play an extremely important role in medicinal chemistry. ${ }^{[9]}$ More specifically, substituted heterocyclic benzo[b]thiophenes, quinolones and carboxamides as very important organic structural motifs, have therefore recently attracted considerable attention from medicinal and synthetic organic chemists due to their spectra of diverse pharmacological features. [1013] Furthermore, abovementioned structural units could be found in a variety of bioactive natural products and numerous of synthetic medical and biochemical agents. As a part of our continuing search for potential anticancer agents structurally related to heterocyclic quinolones, we have previously reported synthesis and strong inhibitory activities on several human tumor cell lines of versatile benzothiophene and thienothiophene carboxanilides and quinolones, thus confirming the anticancer potential of this class of compounds. ${ }^{[14-17]}$

In general, amidino-substituted benzo[ $b]$ thieno[2,3c]quinolones, strong ds-DNA/RNA intercalators, showed in general stronger and more selective antitumor activity than acyclic precursors. Also, we have shown that replacement of the acyclic amidino groups with cyclic amidino 2-imidazolinyl group, respectively, resulted with increased antitumor activity. Furthermore, compounds with high DNA binding capacity were identified as the most promising inhibitors of tumor growth and of topoisomerase activity. ${ }^{[14-17]}$

Guided by all above mentioned compounds, we have chosen selected benzo[ $b]$ thiophene, thieno[2,3- $b]$ thiophene and thieno[3,2-b]thiophene-2-carboxanilides and their cyclic derivatives [2,3-c]quinolones as potential anticancer agents for further biological evaluation. The screened compounds were used as a small platform to compare potential antitumor activity in $2 \mathrm{D}$ and $3 \mathrm{D}$ cancer cell culture system. Our goal was to compare the drug sensitivities of the three human breast cancer cell lines (SK-BR3 , MDA-MB-231, T-47D) grown in 2D and 3D cell culture conditions, and test the hypothesis about differences in activities of chemotherapeutic drugs in 2D and 3D assays. ${ }^{[18]}$

Physicochemical properties of tested compounds have been studied using chromatographic lipophilicity measure, chrom $\log D$, and calculated structural parameters: number of hydrogen bond donors and acceptors, calculated $\log P$ and $\log D$ values, molecular weight, ionization constants $\left(\mathrm{p} K_{\mathrm{a}}\right)$, number of aromatic rings, number of rotatable bonds and polar surface area.

The importance of physicochemical properties of compounds at early stage of discovery of new drugs is now well established. Among these properties, lipophilicity represents one of the most important parameter, since the 
relationship between compounds with anticancer activity and lipophilicity has been investigated for different classes of compounds. ${ }^{[19-21]}$ Lipophilicity measurements by reverse phase chromatography have been already proven as fast and efficient method for compound profiling in the early phase of optimization and results are expressed as Chromatographic $\log D$ (chrom $\log D$ ). ${ }^{[22-24]}$ Association of physicochemical and structural parameters with observed antiproliferative activity was studied with multivariate statistical methods. Classification models for anti-proliferative activity in 2D cell lines were successfully developed and structural contributions to biological activity have been discussed.

\section{MATERIALS AND METHODS}

\section{Chemistry}

The benzo[ $b]$ thieno, thieno[2,3- $b]$ thiophene and thieno[3,2- $b]-$ thiophene 2-carboxanilide compounds 1-20 (Figure 1a) and their cyclic derivatives [2,3-c] quinolones 21-40 (Figure 1b) were previously synthesized and characterized in our research group. ${ }^{[14-16]}$

Starting from corresponding carbonyl-chlorides and substituted anilines, 2-carboxanilides 1-5, 7 and 18-19 were prepared. Amidino substituted derivatives 1-4 and 14-17 were prepared by Pinner reaction from cyano substituted precursors. Quaternary ammonium salts 8-9, 20 and 29-31 were prepared with the excess of $\mathrm{HCl}(\mathrm{g})$ or
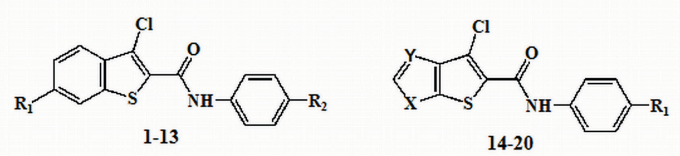

\begin{tabular}{|c|c|c|c|c|}
\hline Comp & $R_{1}$ & $\mathbf{R}_{2}$ & $\mathbf{x}$ & $\mathbf{Y}$ \\
\hline 1 & $\mathrm{H}$ & 2-imidazolinyl & - & - \\
\hline 2 & 2-imidazolinyl & $\mathrm{H}$ & - & - \\
\hline 3 & $\mathrm{H}$ & $i$-propylamidine & - & - \\
\hline 4 & $i$-propylamidine & $\mathrm{H}$ & - & - \\
\hline 5 & $\mathrm{H}$ & $\mathrm{NO}_{2}$ & - & - \\
\hline 6 & $\mathrm{H}$ & $\mathrm{NH}_{2}$ & - & - \\
\hline 7 & $\mathrm{H}$ & $\mathrm{N}\left(\mathrm{CH}_{3}\right)_{2}$ & - & - \\
\hline 8 & $\mathrm{H}$ & $\mathrm{N}^{\top} \mathrm{H}\left(\mathrm{CH}_{3}\right)_{2} \mathrm{Cl}^{-}$ & - & - \\
\hline 9 & $\mathrm{H}$ & $\mathrm{N}^{+}\left(\mathrm{CH}_{3}\right)_{3} \mathrm{I}$ & - & - \\
\hline 10 & $\mathrm{H}$ & $\operatorname{CONH}\left(\mathrm{CH}_{2}\right)_{3} \mathrm{~N}^{+} \mathrm{H}\left(\mathrm{CH}_{3}\right)_{2} \mathrm{Cl}^{-}$ & - & - \\
\hline 11 & $\mathrm{NO}_{2}$ & $\operatorname{CONH}\left(\mathrm{CH}_{2}\right)_{3} \mathrm{~N}^{+} \mathrm{H}\left(\mathrm{CH}_{3}\right) 2 \mathrm{Cl}^{-}$ & - & - \\
\hline 12 & $\mathrm{Br}$ & $\operatorname{CONH}\left(\mathrm{CH}_{2}\right)_{3} \mathrm{~N}^{+} \mathrm{H}\left(\mathrm{CH}_{3}\right)_{2} \mathrm{Cl}^{-}$ & - & - \\
\hline 13 & $\mathrm{CH}_{3}$ & $\operatorname{CONH}\left(\mathrm{CH}_{2}\right) \mathrm{N}^{+} \mathrm{H}\left(\mathrm{CH}_{3}\right) 2 \mathrm{Cl}^{-}$ & - & - \\
\hline 14 & 2-imidazolinyl & - & $\mathrm{s}$ & $\mathrm{CH}$ \\
\hline 15 & 2-imidazolinyl & - & $\mathrm{CH}$ & $\mathrm{s}$ \\
\hline 16 & $i$-propylamidine & - & $\mathrm{s}$ & $\mathrm{CH}$ \\
\hline 17 & $i$-propylamidine & - & $\mathrm{CH}$ & $\mathrm{s}$ \\
\hline 18 & $\mathrm{NO}_{2}$ & - & $\mathrm{s}$ & $\mathrm{CH}$ \\
\hline 19 & $\mathrm{~N}\left(\mathrm{CH}_{3}\right)_{2}$ & - & $\mathrm{s}$ & $\mathrm{CH}$ \\
\hline 20 & $\mathrm{NH}^{+} \mathrm{H}\left(\mathrm{CH}_{3}\right)_{2} \mathrm{Cl}^{-}$ & - & $\mathrm{s}$ & $\mathrm{CH}$ \\
\hline
\end{tabular}

methyl-iodide while amino substituted derivative 6 was prepared by reduction of nitro analogues and 28 by acidic hydrolysis of 32. Cyclic derivatives [2,3-c]quinolones, 2122, 25, 27, 32-38 and 40 obtained by photochemical cyclization from acyclic precursors. $\mathrm{N}$-alkylated derivatives 23-24, 30-31 and 39 were synthesized due to the alkylation with methyl-iodide. Acyclic compounds bearing $N, N$ dimethyaminopropyl-amide side chain on phenyl ring 1013 were prepared in the reaction with $N, N$-dimethyamino1-propylamine which gave in the photochemical cyclization substituted [2,3-b]quinolones 34-37.

\section{SYNTHESIS}

The synthesis and spectroscopic characterization of compounds 1-40 was previously published in our research group. ${ }^{[14-17]}$

\section{CHROM $\log D$ DETERMINATION}

Chrom $\log D$ values were determined from the following equation: chrom $\log D=0.0857 \times \mathrm{CHI}-2$ (ref. Chromatographic Hydrophobic Index (CHI) values have been determined from gradient retention times $\left(t_{\mathrm{R}}\right)$ as described by Valkó and Slegel.[25] These values approximately correspond to the volume percentage of organic component in the mobile phase when the compound elutes. $\mathrm{CHI}$ values were determined at $\mathrm{pH} 2.7$ and 7.4. Chromatograms were obtained using an Agilent 1100 Series HPLC instruments equipped with diode array detector (DAD) coupled with Micromass Quattro API mass spectrometer. Data_acquisition b

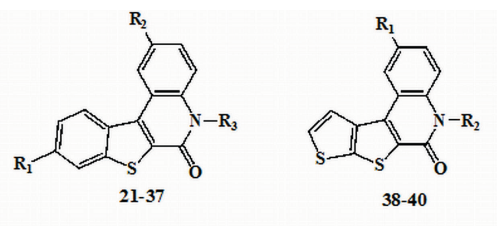

Figure 1. a) Structures of benzo[b]thieno-, thieno[2,3-b]thiophene- and thieno[3,2-b]thiophene 2-carboxanilides 1-20. b) Structures of [2,3-c]quinolones 21-40. 
and processing were performed with MassLynx software version 4.1. The column used for $\mathrm{CHI}$ determination was Luna C18 $(50 \mathrm{~mm} \times 3 \mathrm{~mm}$ i.d., $5 \mu \mathrm{m}$ particle size, $100 \AA$ ). The aqueous part of the mobile phase was $50 \mathrm{mM}$ ammonium acetate adjusted with ammonia solution to $\mathrm{pH} 7.4$ and $0.1 \%(v / v)$ formic acid in water for $\mathrm{pH}$ 2.7. As an organic part of their mobile phase acetonitrile was used. The mobile phase flow rate was $1 \mathrm{~mL} \mathrm{~min}{ }^{-1}$ for all measurements. The gradient retention times $t_{R}$ were measured under the following gradient condition: 0 to $3 \mathrm{~min}$ linear gradient from 0 to $100 \%$ acetonitrile; 3 to $3.5 \mathrm{~min} 100 \%$ acetonitrile; 3.5 to $3.7 \mathrm{~min}$ from 100 to $0 \%$ acetonitrile; and 3.7 to $5 \mathrm{~min}$ re-equilibration time with $100 \%$ of aqueous part of the mobile phase.

\section{Antitumor Activity Assays}

To compare the difference in compound anti-proliferative activity we have tested 40 benzo[b]thieno, thieno[2,3$b]$ thiophene and thieno[3,2-b]thiophene 2-carboxanilides and their cyclic derivatives [2,3-c] quinolones in 2D and 3D cell assays. Control compound in both assays was doxorubicin, an anthracycline antibiotic that intercalate into DNA double helical structure.

For 2D cell assay we used traditional two-dimensional in vitro cancer cell line proliferation assay, one of the most widely used assay for evaluating preliminary anticancer activity of new chemical entities (NCE). As a 3D assay we used hanging drop proliferation cell assay.

\section{CELL CULTURES}

Human breast cancer cell lines SK-BR-3 (HTB-30), MDA-MB231 (HTB-26) and T-47D (HTB-133) were purchased from ATCC and were maintained in appropriated, recommended manner by using supplier medium, supplemented with $10 \%$ heat inactivated fetal bovine serum and penicillin / streptomycin / amphotericin $\mathrm{B}$, in a humidified atmosphere of $5 \% \mathrm{CO}_{2}$ and $95 \% \mathrm{O}_{2}$ at $37^{\circ} \mathrm{C}$.

\section{TEST COMPOUNDS AND STANDARD COMPOUND}

Doxorubicin was purchased from Apollo (BID0120; Opelika, $\mathrm{AL}$ ). Test compounds were synthesized by research group at Department of Organic Chemistry, Faculty of Chemical Engineering and Technology, University of Zagreb.

Mother plates (96-well-V plates, polypropylene, Greiner Bio-one, Cat. 651201) with serial dilutions of compounds in pure DMSO are prepared from $10 \mathrm{mM}$ DMSO stock solutions on Janus automatic pipetting workstation (Perkin-Elmer). Compounds were diluted $1: 3.300 \mathrm{~nL}$ of compound were transferred from mother plate to test plate by using Mosquito (TTP labtech). DMSO percentage in test concentrations was $0.3 \%$. Final starting concentration of the standard compound and test compounds was $30 \mu \mathrm{M}$ (other concentrations were: $10 \mu \mathrm{M}, 3.33 \mu \mathrm{M}, 1.11 \mu \mathrm{M}$, $0.37 \mu \mathrm{M}, 0.12 \mu \mathrm{M}, 0.04 \mu \mathrm{M}$ and $0.014 \mu \mathrm{M})$.

\section{D AND 3D DRUG SCREENING SETUP}

To determine the influence of testing compounds on the cell viability drug sensitivity testing was performed in 2D and in 3D cell culture format. 2D and 3D drug screening setup was done as published before. ${ }^{[7]}$ In brief, for 2D cell culture assay, cells were grown in 96-well cell star polystyrene plates, by using 10000 cells per well, seeded $4 \mathrm{~h}$ prior the treatment with different compounds concentrations and incubated for $72 \mathrm{~h}$. For 3D cell culture assay, cells were grown in 96-well Perfecta 3D hanging drop plates, by using 5000 cells per well, seeded and incubated 4 days, until spheres were formed (checked under the microscope). After sphere formation, cells were treated with compounds followed by $72 \mathrm{~h}$ incubation.

A cell viability assay was performed according to the manufacturer's instruction, using CellTiter ${ }^{\circledR} 96$ Aqueous One Solution Cell Proliferation Assay, MTS kit, (Promega, Madison, WI). After $0.5-2 \mathrm{~h}$ of cell incubation with MTS, the plates were read using Perkin Elmer ${ }^{\circ}$ EnVision 2104 at $490 \mathrm{~nm}$. The results for each of tested compounds are reported as growth percentages from three independent concentrations curves compared with the untreated control cells after drug exposure.

\section{STATISTICAL ANALYSIS}

Calculation of $\mathrm{IC}_{50}$ data, curves and $\mathrm{QC}$ analysis is made by using Excel tools and GraphPadPrism software (La Jolla, CA), v. 5.03. In brief, individual concentration-effect curves are generated by plotting the logarithm of the tested concentration of tested compounds $(X)$ versus corresponding percent inhibition values $(\mathrm{Y})$ using least squares (ordinary) fit. Best fit $\mathrm{IC}_{50}$ values are calculated using Log(inhibitor) versus normalized response - Variable slope equation, where $Y=100 /\left(1+10\left(\left(\log \mid C_{50}-X\right) *\right.\right.$ HillSlope $\left.)\right)$. QC criteria parameters $\left(Z^{\prime}, S: B, R^{2}\right.$, HillSlope) were checked for every $\mathrm{IC}_{50}$ curve.

\section{COMPUTATIONAL METHODS}

Computational analysis of biological results has been performed using Vortex and Simca software's (v. P-11, Malmo, Sweden) from Umetrics. Simple structural parameters were calculated using ACD / Percepta software (v. 2015, Toronto, ON) from ACD / Labs; molecular weight, $c \log P, \operatorname{cog} D$, number of hydrogen bond acceptors and number of hydrogen bond donors, number of aromatic rings, number of halogen atoms and $\mathrm{p} K_{\mathrm{a}}$. Principal component analysis (PCA), partial least square analysis (PLS) and partial least square discriminant analysis has been used to build a statistical models for $2 \mathrm{D}$ and $3 \mathrm{D}$ antiproliferative effect. Field based alignment has been performed with the Torch software (v. 10.4, Litlington, UK) from Cresset. 


\section{RESULTS AND DISCUSSION}

\section{Spherical Growth of Breast Cancer Cell Lines in 3D Conditions}

To prove that selected breast cancer cell lines can form spheres or growth in spherical manner in 3D conditions we followed the growth of each during 6 days from cells seeding. Formation of spherical growth of MDA-MB-231, SK-BR-3 and T-47D cells in 3D format during period of 6 days (4-5x magnification, seeding density 5000 cells / well) are presented on Figure 2. From obtained results we concluded that for all three cell lines on day 4 from cell seeding treatment with compounds can started.

\section{Differences in Drug Responses Between 2D and 3D Culture Models}

Antitumor activity of compounds $\mathbf{1 - 4 0}$ were tested in 2D and $3 \mathrm{D}$ cell cultures. As control or standard compound we use doxorubicin due to similar mode of action to tested

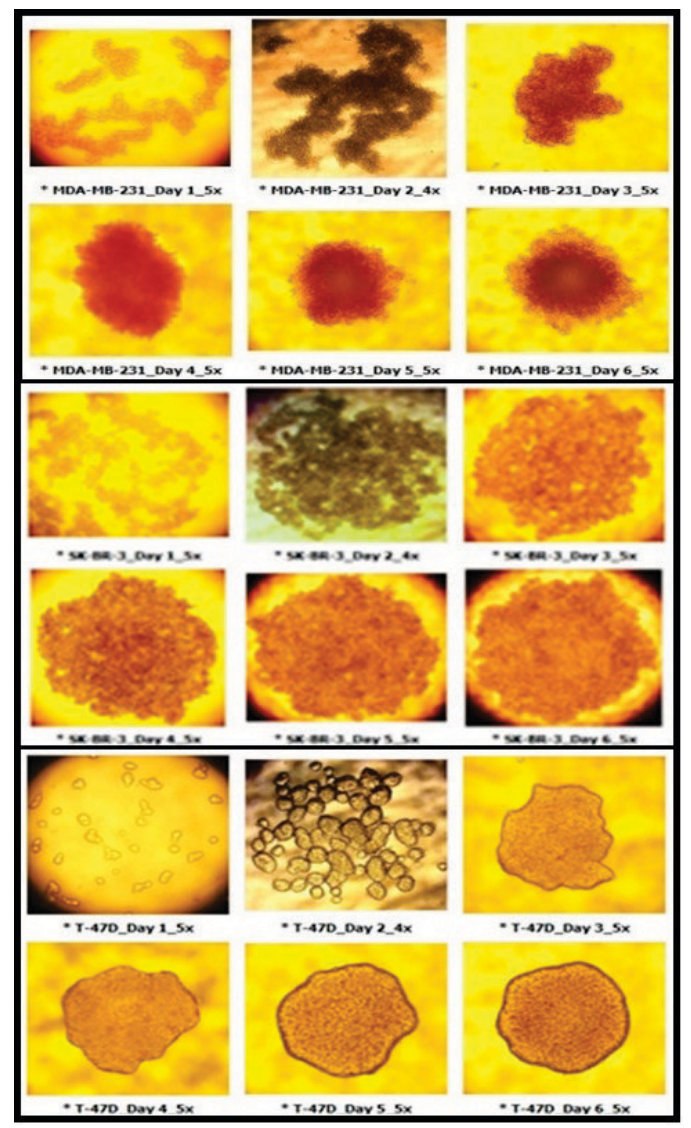

Figure 2. Formation of spherical growth of MDA-MB-231 (up), SK-BR-3 (middle) and T-47D (down) cells in 3D format during period of 6 days (4-5x magnification, seeding density 5000 cells / well).[32] compounds ${ }^{[26]}$. In this set up of assays, doxorubicin showed higher $I_{50}$ values in $3 \mathrm{D}$ assays on all three cell lines (for MDA-MB-231 $0.23 \pm 0.07 \mu \mathrm{M}$; SK-BR-3 $1.29 \pm 0.16 \mu \mathrm{M}$; and T-47D 1.01 $\pm 0.13 \mu \mathrm{M}$ ) compared to $\mathrm{IC}_{50}$ values in $2 \mathrm{D}$ assays (for MDA-MB-231 $0.16 \pm 0.07 \mu \mathrm{M}$; SK-BR-3 $0.1 \pm 0.02 \mu \mathrm{M}$; and T-47D $0.08 \pm 0.01 \mu \mathrm{M})$ ). However, on MDA-MB-231 cell line $\mathrm{IC}_{50}$ value of doxorubicin were only slightly higher in $3 \mathrm{D}$ assay when compared with $\mathrm{IC}_{50}$ obtained in $2 \mathrm{D}$ assay (Figure 3 / Table 1).

The highest discrepancy of $I_{50}$ values for doxorubicin was obtained on T47D cell line $(0.08 \pm 0.01 \mu \mathrm{M}$ in $2 \mathrm{D}$ and $1.01 \pm 0.13 \mu \mathrm{M}$ in $3 \mathrm{D})$. Therefore, we concluded that MDA-MB-231 cell line is most susceptible and the T47D cell line more resistant in comparison with other two. For doxorubicin the obtained $\mathrm{IC}_{50}$ values in $2 \mathrm{D}$ assay were comparable with $\mathrm{IC}_{50}$ values found in the literature, ${ }^{[27-29]}$ taking in account the differences in assay setup (number of cells per well, cell line sensitivity, source and formulation of tested standard drugs, washout period, cell passage number, etc.). Related to 3D assay, $I C_{50}$ values in a 3D cell culture models depends, besides all other known factors,
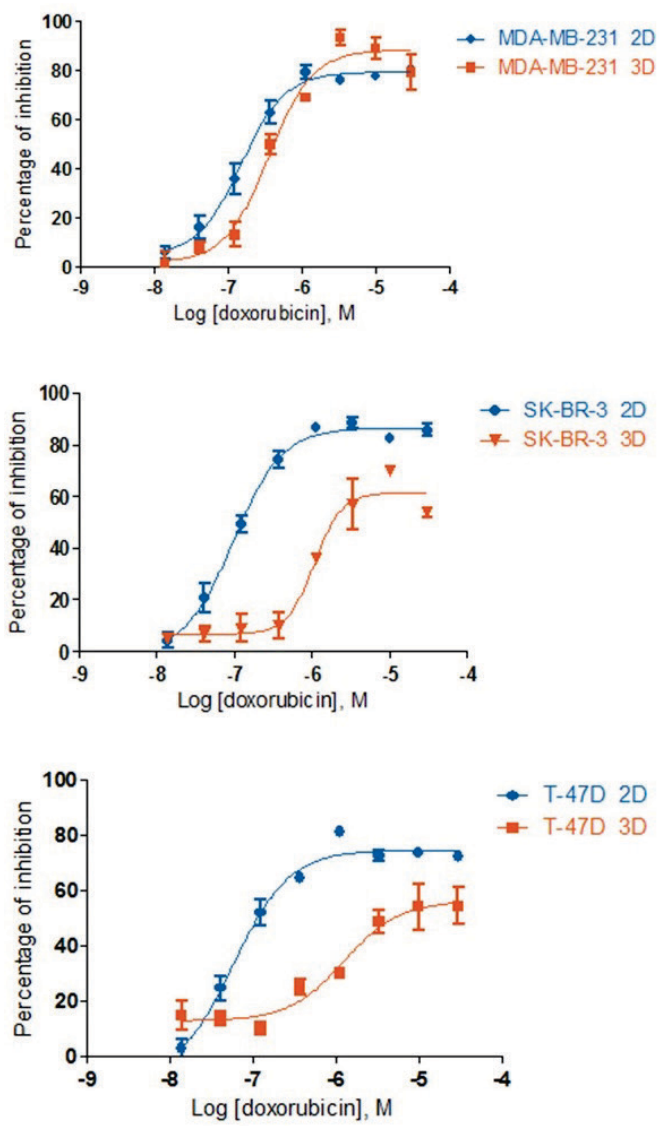

Figure 3. Doxorubicin dose-response profiles obtained on 2D and 3D cell culture assay of MDA-MB-231, SK-BR-3 and T-47D breast cancer cell lines after $72 \mathrm{~h}$ incubation. 
Table 1. Antitumor activity of compounds 1-40 and control compound (Doxorubicin) in 2D and 3D cell cultures (MDA-MB-231, SK-BR-3 and T-47D breast cancer cell lines), after $72 \mathrm{~h}$ of incubation with tested compounds..

\begin{tabular}{|c|c|c|c|c|c|c|}
\hline \multirow{3}{*}{$\mathrm{Cpd}$} & \multicolumn{6}{|c|}{$\mathrm{IC}_{50} / \mu \mathrm{M} \pm \mathrm{SD} ; N=3$} \\
\hline & \multicolumn{2}{|c|}{ MDA-MB-231 } & \multicolumn{2}{|c|}{ SK-BR-3 } & \multicolumn{2}{|c|}{ T47D } \\
\hline & $2 \mathrm{D}$ & $3 \mathrm{D}$ & $2 \mathrm{D}$ & $3 \mathrm{D}$ & $2 \mathrm{D}$ & $3 \mathrm{D}$ \\
\hline 1 & $5 \pm 0.56$ & $2 \pm 0.22$ & $3 \pm 0.16$ & 21 & $5 \pm 0.14$ & $18 \pm 3.17$ \\
\hline 2 & $9 \pm 0.06$ & $3 \pm 0.58$ & $5 \pm 0.05$ & $>30$ & $7 \pm 0.4$ & $20 \pm 3.70$ \\
\hline 3 & $11 \pm 1.64$ & $16 \pm 0.56$ & $10 \pm 0.31$ & $>30$ & $16 \pm 0.41$ & $>30$ \\
\hline 4 & $10 \pm 0.09$ & $15 \pm 0.50$ & $13 \pm 0.74$ & $>30$ & $18 \pm 0.54$ & $>30$ \\
\hline 5 & $>30$ & $>30$ & $>30$ & $>30$ & $>30$ & $>30$ \\
\hline 6 & $>30$ & $>30$ & $>30$ & $>30$ & $>30$ & $>30$ \\
\hline 7 & $>30$ & $>30$ & $>30$ & $>30$ & $>30$ & $>30$ \\
\hline 8 & $>30$ & $>30$ & $>30$ & $>30$ & $>30$ & $>30$ \\
\hline 9 & $>30$ & $>30$ & $>30$ & $>30$ & $>30$ & $>30$ \\
\hline 10 & $9 \pm 0.10$ & $14 \pm 1.9$ & $11 \pm 0.44$ & $>30$ & $14 \pm 0.15$ & $>30$ \\
\hline 11 & $2 \pm 0.40$ & $12.5 \pm 0.9$ & $0.96 \pm 0.16$ & $>30$ & $5 \pm 0.66$ & $>30$ \\
\hline 12 & $6 \pm 1.91$ & $21 \pm 4.1$ & $4 \pm 0.05$ & $27 \pm 0.41$ & $5 \pm 0.85$ & $>30$ \\
\hline 13 & $5 \pm 0.29$ & $>30$ & $4 \pm 0.3$ & $>30$ & $4 \pm 0.46$ & $>30$ \\
\hline 14 & $5 \pm 0.12$ & $3 \pm 0.03$ & $5 \pm 0.12$ & $>30$ & $5 \pm 0.25$ & $13 \pm 2.00$ \\
\hline 15 & $12 \pm 0.13$ & $8 \pm 2.56$ & $15 \pm 0.38$ & $>30$ & $13 \pm 1.43$ & $>30$ \\
\hline 16 & $12 \pm 0.30$ & $17 \pm 0.88$ & $17 \pm 0.84$ & $>30$ & $13 \pm 0.3$ & $>30$ \\
\hline 17 & $12 \pm 0.08$ & $15 \pm 0.79$ & $15 \pm 0.34$ & $>30$ & $24 \pm 0.4$ & $>30$ \\
\hline 18 & $>30$ & $>30$ & $0.34 \pm 0.16$ & $>30$ & $>30$ & $>30$ \\
\hline 19 & $>30$ & $>30$ & $0.43 \pm 0.18$ & $>30$ & $>30$ & $>30$ \\
\hline 20 & $>30$ & $>30$ & $1.08 \pm 0.33$ & $>30$ & $>30$ & $>30$ \\
\hline 21 & $2 \pm 0.10$ & $2 \pm 0.20$ & $4 \pm 0.23$ & 26 & $6 \pm 0.62$ & $>30$ \\
\hline 22 & $4 \pm 0.37$ & $7 \pm 0.90$ & $5 \pm 0.12$ & 22 & $14 \pm 0.27$ & $>30$ \\
\hline 23 & $3 \pm 0.81$ & $3 \pm 0.83$ & $3 \pm 0.47$ & 19 & $5 \pm 0.22$ & $18 \pm 5.20$ \\
\hline 24 & $4 \pm 0.85$ & $2 \pm 0.43$ & $4 \pm 0.10$ & $>30$ & $6 \pm 0.1$ & $16 \pm 4.20$ \\
\hline 25 & $11 \pm 0.38$ & $>30$ & $8 \pm 0.45$ & $>30$ & $18 \pm 0.09$ & $>30$ \\
\hline 26 & $12 \pm 2.10$ & $>30$ & $4 \pm 0.17$ & $>30$ & $12 \pm 0.37$ & $>30$ \\
\hline 27 & $>30$ & $>30$ & $0.34 \pm 0.19$ & $>30$ & $>30$ & $>30$ \\
\hline 28 & $11 \pm 0.64$ & $4.8 \pm 0.84$ & $7 \pm 0.16$ & $>30$ & $>30$ & $>30$ \\
\hline 29 & $>30$ & $>30$ & $>30$ & $>30$ & $>30$ & $>30$ \\
\hline 30 & $>30$ & $6.95 \pm 1.3$ & $>30$ & $>30$ & $>30$ & $>30$ \\
\hline 31 & $>30$ & $>30$ & $>30$ & $>30$ & $>30$ & $>30$ \\
\hline 32 & $>30$ & $>30$ & $0.78 \pm 0.28$ & $>30$ & $>30$ & $>30$ \\
\hline 33 & $1 \pm 0.22$ & $20 \pm 1.71$ & $4 \pm 0.18$ & $>30$ & $>30$ & $>30$ \\
\hline 34 & $11 \pm 1.69$ & $15 \pm 1.16$ & $9 \pm 1.15$ & $>30$ & $14 \pm 1.33$ & $>30$ \\
\hline 35 & $10 \pm 0.31$ & $25 \pm 0.53$ & $6 \pm 0.31$ & $>30$ & $14 \pm 0.44$ & $>30$ \\
\hline 36 & $2 \pm 0.44$ & $12 \pm 0.63$ & $3 \pm 0.13$ & $>30$ & $6 \pm 2.21$ & $>30$ \\
\hline 37 & $3 \pm 0.14$ & $>30$ & $7 \pm 1.78$ & $>30$ & $>30$ & $>30$ \\
\hline 38 & $4 \pm 0.05$ & $14 \pm 4.5$ & $6 \pm 0.26$ & 29 & $12 \pm 0.23$ & $>30$ \\
\hline 39 & $3 \pm 0.56$ & $6 \pm 2.17$ & $5 \pm 0.03$ & $>30$ & $8 \pm 0.63$ & $>30$ \\
\hline 40 & $>30$ & $>30$ & $>30$ & $>30$ & $>30$ & $>30$ \\
\hline Doxorubicin & $0.16 \pm 0.07$ & $0.23 \pm 0.07$ & $0.1 \pm 0.02$ & $1.29 \pm 0.16$ & $0.08 \pm 0.01$ & $1.01 \pm 0.13$ \\
\hline
\end{tabular}


on spheroid growth and/or forming of sphere. As is showed on Figure 2, MDA-MB-231 and SK-BR-3 growth has an spherical shape, but T-47D forms spheres with basal membrane around it, and this can have an impact on $\mathrm{IC}_{50}$ values discrepancy. Quality parameters for 2D and 3D assays $\left(Z^{\prime}\right.$ and $S: B$ ) were within standard expected values for all three cell lines. Standard $Z^{\prime}$ for cell in vitro assays from 0.35 to1, signal to background > 1.5 and hillslope between 0.5 and 5 .

For tested compounds, we obtained the variations in responses in 2D and $3 \mathrm{D}$ cell culture system for all three breast cancer cell lines (Table 1 ). In general, $I_{C_{50}}$ values from $3 \mathrm{D}$ assay were higher in comparison with $I C_{50}$ values obtained in 2D cell model, which means that compounds were less active in 3D cellular assay models. Exceptions were only compounds 15, 28 and $\mathbf{3 0}$ on MDA-MB-231 cell line. Eight compounds were highly active in both $2 D$ and $3 D$ test formats $(\mathbf{1}, \mathbf{2}, \mathbf{1 4}, \mathbf{2 1}, \mathbf{2 2}, \mathbf{2 3}, \mathbf{2 4}, \mathbf{3 9})$, but only on MDAMB-231 cell line. However, none of these compounds showed such a profile on SK-BR-3 and T47D cell lines. Most of the compounds were highly active in 2D format assay, but in 3D format assay the same compounds showed moderate or no activity. Such activity pattern was observed for 12 compounds on MDA- MA-231 $(\mathbf{3}, \mathbf{4}, \mathbf{1 0}, \mathbf{1 1}, \mathbf{1 2}, \mathbf{1 3}, \mathbf{2 5}$, $33,36,37,38,39), 25$ compounds on SK-BR-3 cell line (1, $2,11,12,13,14,18,19,20,21,22,23,24,25,26,27,28$, $32,33,34,35,36,37,38,39$ ) and 11 compounds on T47D cell line $(1,2,11,12,13,14,21,23,24,3639)$. Compounds 11,12 and 13 were active on all three cell lines in 2D format assay.

In general, there was poor or no trend between $\mathrm{IC}_{50}$ values on $2 D$ and $3 D$ assays format suggesting that $3 D$ assay provided different potency information in comparison with $2 \mathrm{D}$ assay. On Figure $4 \mathrm{IC} \mathrm{C}_{50}$ values (dots) of 40 NCEs in $2 \mathrm{D}$ and $3 \mathrm{D}$ format cell culture assay on MDA-MB-231, SK-BR-3 and T-47D cells are presented. If we compare number of active compounds on each cell lines in both assay formats, the
Table 2. Correlation between collected biological data (antiproliferative activity for 40 compounds, 2D vs. 3D).

\begin{tabular}{|c|c|c|c|c|c|c|}
\hline${ }^{\prime} C_{50}(\mu \mathrm{M}) / r$ & $\begin{array}{c}2 \mathrm{D} \\
\mathrm{MDA}- \\
\mathrm{MB}-231\end{array}$ & $\begin{array}{c}2 D \\
\text { SK-BR-3 }\end{array}$ & $\begin{array}{c}2 D \\
T-47 D\end{array}$ & $\begin{array}{c}\text { 3D } \\
\text { MDA- } \\
\text { MB-231 }\end{array}$ & $\begin{array}{c}3 D \\
\text { SK-BR-3 }\end{array}$ & $\begin{array}{c}3 D \\
T-47 D\end{array}$ \\
\hline $\begin{array}{l}\text { 2D MDA- } \\
\text { MB-231 }\end{array}$ & & 0.6 & 0.801 & 0.666 & 0.374 & 0.337 \\
\hline 2D SK-BR-3 & 0.6 & & 0.52 & 0.334 & 0.274 & 0.26 \\
\hline $2 \mathrm{D} T-47 \mathrm{D}$ & 0.801 & 0.52 & & 0.662 & 0.439 & 0.501 \\
\hline $\begin{array}{l}\text { 3D MDA- } \\
\text { MB-231 }\end{array}$ & 0.666 & 0.334 & 0.662 & & 0.521 & 0.588 \\
\hline 3D SK-BR-3 & 0.374 & 0.274 & 0.439 & 0.521 & & 0.549 \\
\hline 3D T-47D & 0.337 & 0.26 & 0.501 & 0.588 & 0.549 & \\
\hline
\end{tabular}

most of the compounds showed significant activity on MDA-MB-231 cell line, and lower activity profile on SK-BR and T47D cell lines which is in line with cell line susceptibility / resistance. Statistical correlation of compounds $I C_{50}$ values on 2D and 3D assays format is presented in Table 2. The best correlation between $\mathrm{IC}_{50}$ values on $2 \mathrm{D}$ and $3 \mathrm{D}$ assays format is on MDA-MB-231 cell line (0.666) than for T47D (0.501) and then for SK-Br-3 (0.274).

\section{Structure-Activity Relationship (SAR) in 2D Assays}

The results obtained from the evaluation of antitumor activity in the 2D assays revealed that some of tested compounds showed very pronounced selective activity in submicromolar concentrations range on SK-BR-3 cell lines. Among acyclic derivatives, compounds showed to be the most selective and active were thieno[2,3-b]thiophene-2carboxamides bearing nitro $\left(18, \mathrm{IC}_{50}=0.34 \mu \mathrm{M}\right), \mathrm{N}, \mathrm{N}$ dimethylamino $\left(19, \mathrm{IC}_{50}=0.43 \mu \mathrm{M}\right)$ and protonated $\mathrm{N}, \mathrm{N}$ dimethylamino group $\left(20, \mathrm{IC}_{50}=1.08 \mu \mathrm{M}\right)$, and nitro substituted benzo[b]thieno-2-carboxamide bearing amide side chain $\left(\mathbf{1 1}, \mathrm{IC}_{50}=0.96 \mu \mathrm{M}\right)$. Furthermore, the same
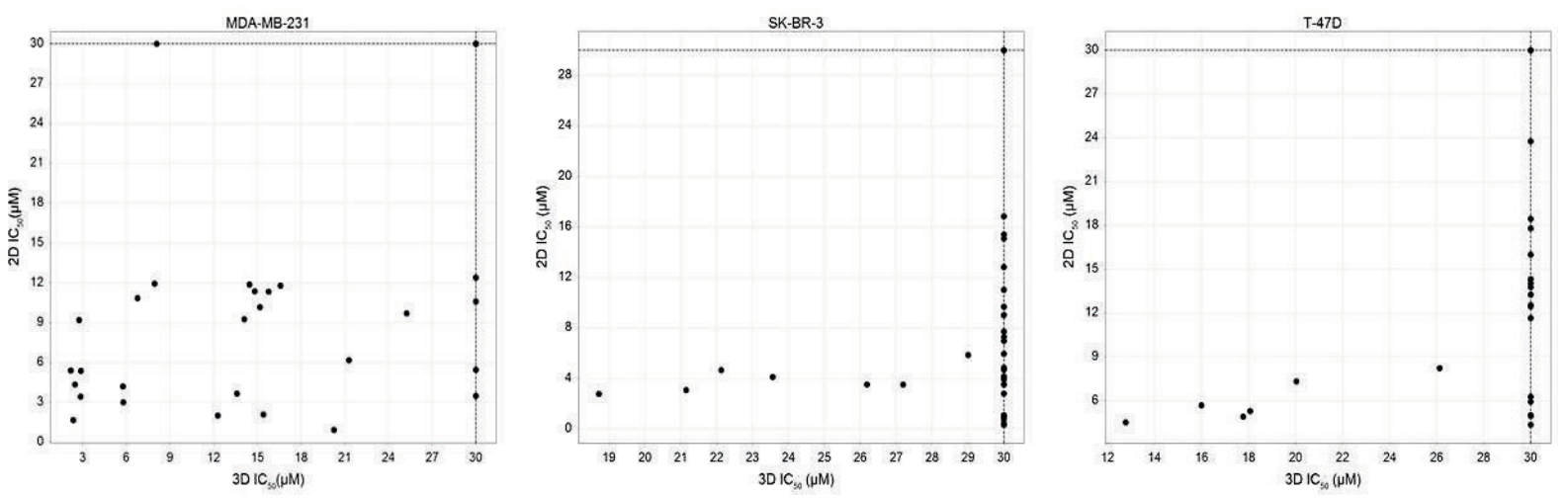

Figure 4. Correlation of $I C_{50}$ values obtained in $2 \mathrm{D}$ and $3 \mathrm{D}$ assay format for three breast cancer cell lines MDA-MB-231 (left), SKBR-3 (middle) and T-47D (right) after $72 \mathrm{~h}$ incubation with tested compounds. Highest concentration used is $30 \mu \mathrm{M}$. 
selectivity and activity was also displayed by cyclic nitro (27, $\left.\mathrm{IC}_{50}=0.34 \mu \mathrm{M}\right)$ and $N$-acetamido $\left(32, \mathrm{IC}_{50}=0.78 \mu \mathrm{M}\right)$ substituted benzo[b]thieno[2,3-c]quinolones. In general, both acyclic and cyclic amidino substituted 2-carboxamides and quinolones bearing cyclic 2-imidazolinyl amidine group 1$\mathbf{2}, \mathbf{1 4}-\mathbf{1 5}, \mathbf{2 1 - 2 4}$ and 38-39 were more active in comparison with the same analogues bearing isopropylamidine group 3-4, 16-17, 25-26 and 40. This was in good agreement with our previous presumption that replacement of the acyclic amidino groups with cyclic amidino 2-imidazolinyl group, respectively, resulted with increased antitumor activity. Also, $\mathrm{N}$-methylation of cyclic 2-imidazolinyl substituted derivatives 23-24 and $\mathbf{3 9}$ slightly increased the antitumor activity. In general, translation of the amidino groups from the anilide or quinolone to benzo[b]thiophene part of the molecule did not significantly influence the activity. Amino substituted benzo[ $b$ ] thieno[2,3-c]quinolone $\mathbf{2 8}$ showed the increased activity on MDA-MB-231 cell line in comparison to the nitro analogue 27. Compared to $\mathrm{N}$-acetamido cyclic derivative 32, $\mathrm{N}$-alkylated $\mathrm{N}$-acetamido cyclic derivative 33, as the most active one among all tested compounds, showed significant decrease of activity on SK-BR-3 cell line, as well as improved activity on MDA-MB-231 cell line. Moreover, benzo[b]thieno-2-carboxanilides substituted with nitrogen-bearing substituents 5-9 together with cyclic benzo[b]thiophenes prepared as quaternary ammonium salts 29-31 and isopropyl-amido substituted thieno[2,3$b]$ thieno[2,3-c]quinolone $\mathbf{4 0}$ were inactive against all cancer cell lines.

Since some of investigated compounds were characterised as DNA intercalators, ${ }^{[14-17]}$ due to their characteristic structural features containing flat aromatic regions as well as positively charged basic centre, field based overlay and comparison of daunorubicin complex with DNA and some of the most potent compounds have been performed (Figure 5). Molecular field technology is particularly useful for comparison of diverse chemotypes with analogous mode of action and provide a way to understand how the surface properties of molecules with underlying atomic structure can be translated into biologically relevant binding properties. ${ }^{[30]}$

Figure 5a displays molecular field distribution for daunorubicin in bioactive conformation and compound $\mathbf{3 6}$. Both compounds are characterised with polarisation of electrostatic contributions with red being positive potential and blue negative. Hydrophobic aromatic core, shown in yellow is placed in between these regions.

Although structural similarity for the whole molecule is not high, major structural features do overlap and molecular field similarity is much higher indicating possible analogous binding mode. Field overlap analysis indicates that further structural optimisations might introduce a spacer between cyclic 2-imidazolinyl amidine group and acyclic

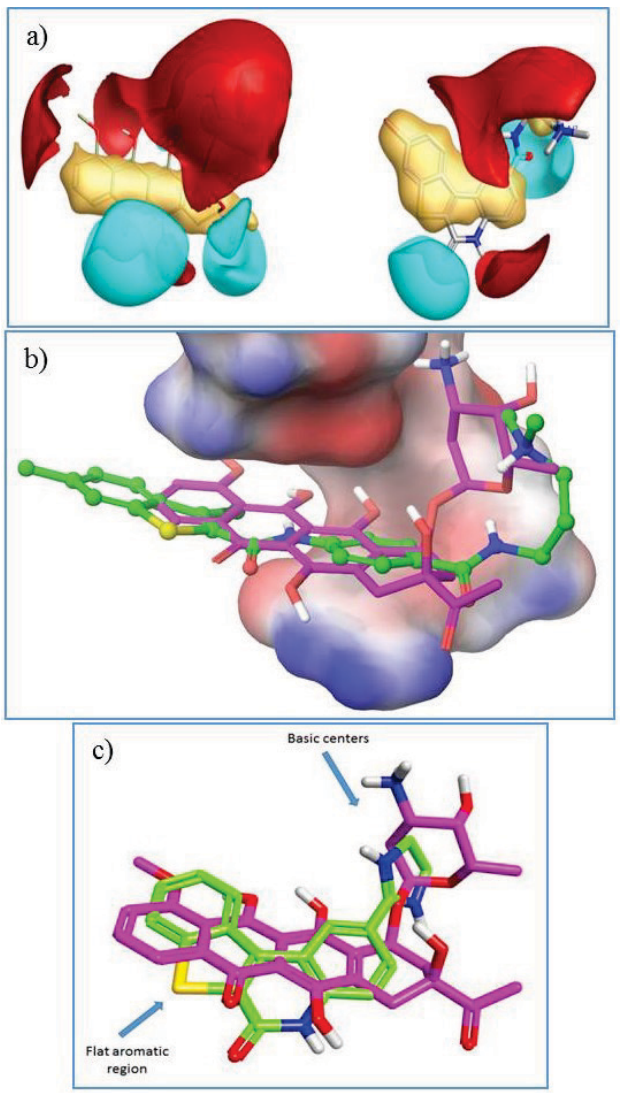

Figure 5. a) Molecular field overlay of compound 36 with daunorubicin. Structure of daunorubicin is taken from its complex with DNA ( $p d b$ : ID11). Positive electrostatic potential is shown in red, negative electrostatic potential is shown in blue and hydrophobic regions are shown in yellow; b) Field-based alignment of bioactive conformation for daunorubicin (magenta) in complex with DNA (shown as a surface color coded by electrostatic potential with acidic regions as red and basic regions as blue) and compound 36 (in green); c) Field-based alignment of compound 2 (green) with daunorubicin (magenta).

and cyclic amidino substituted 2-carboxamides and quinolones improving alignment of pharmacophoric features.

\section{Structure-Activity Relationship (SAR) in 3D Assays}

As it can be viewed from the Table 1, results obtained from the evaluation of antitumor activity in the $3 \mathrm{D}$ cell culture systems indicated the selective activity of some tested compounds on MDA-MB-231 cell line. The most active compounds among all tested showed to be acyclic (1) and cyclic (21) benzo[b]thiophene derivatives bearing 2-imidazolinyl group at the anilide and quinolone part of the molecule, with $\mathrm{IC}_{50}=2.0 \mu \mathrm{M}$. In addition, isopropyl-amidino 
substituted derivatives, both acyclic (3-4 and 16-17) and cyclic (25-26 and 40), were less active than 2-imidazolinyl substituted derivatives as it was expected. 2-imidazolinyl substituted thieno[2,3-b]thiophene-2-carboxamides 14 and $\mathbf{1 5}$ showed also pronounced activity slightly decrease in comparison to their benzo[b]thiophene analogues. Furthermore, moderate activity on MDA-MB-231 cell line was observed with compounds bearing $\mathrm{N}, \mathrm{N}$-dimethylamino-1-propyl amide side chain on anilide (10-13) and quinolone (34-36) part of the molecule with the exception of methyl substituted cyclic derivative $\mathbf{4 0}$ which was inactive. Benzo[ $b]$ thiophene-2-carboxanilides 5-9 and thieno[2,3-b] thiophene-2-carboxanilides $\mathbf{1 8 - 2 0}$, as well as benzo[b]thieno[2,3-c]quinolones $\mathbf{2 7}, \mathbf{2 9}$ and $\mathbf{3 1 - 3 2}$, substituted with nitrogen-bearing substituents, were inactive on all tested cell lines. Cyclic derivatives bearing amino group (28) and protonated $\mathrm{N}, \mathrm{N}$-dimethylamino group (30) also showed very pronounced antitumor activity on the same cell line. Compounds bearing 2-imidazolinyl substituent either on anilide (1-2 and 14) or quinolone part of the molecule (23-24) displayed also moderate activity on T-47D cell line as well as on SK-BR-3 cell line (1, 21-23 and 38).

\section{Influence of Physico-Chemical Properties on Anti-Proliferative Activity in 2D and 3D Cell Culture Assay}

Anti-proliferative activity for 40 compounds (2D vs. 3D) has been analysed in terms of measured and calculated lipophilicity values and number of simple 2D descriptors describing structural variations among the current data set.

Anti-proliferative activity on MDA-MB-231 (2D) cells correlates well with T-47D (2D) $(r=0.8)$ and somewhat less with SK-BR-3 (2D) ( $r=0.6)$. Correlation between 2D and 3D cells is weaker, that might be a result of lower cell permeation in $3 \mathrm{D}$ cultures resulting in shift of activity distribution toward higher $I_{50}$ values. Inter-correlation between collected biological data is shown in Table 2 . Antiproliferative activity measured for the MDA-MB-321 (2D) cells correlate best with other cell types. The MDAMB-321 (2D) cells are also most sensitive ones. Therefore, more detailed analysis for this particular cell type has been performed.

As an initial attempt to rationalise SAR of antitumor activity for benzothiophene and thienothiophene carboxanilides and quinolones in a semi-quantitative, and possibly predictive way, influence of physicochemical and structural properties on anti-proliferative activity has been investigated. As an experimental measure of lipophilicity, chromLogD values (Table 3) were used together with a number of calculated structural descriptors: molecular weight, $\operatorname{cog} P, \operatorname{cog} D$, number of hydrogen bond acceptors and number of hydrogen bond donors, number of aromatic rings, number of halogen atoms and $\mathrm{p} K_{\mathrm{a}}$.
Table 3. Chrom $\log D$ values determined from the following equation: chrom $\log D=0.0857 \times \mathrm{CHI}-2$. Chromatographic Hydrophobic Index (CHI) values have been determined from gradient retention times $\left(t_{R}\right)$ at $\mathrm{pH} 7.4$ and $\mathrm{pH}$ 2.7. Values for compounds 15 and 30 were not determined, due to lack of signals in chromatograms.

\begin{tabular}{|c|c|c|c|c|c|}
\hline Cpd & $\begin{array}{c}\text { Chrom } \\
\log D 7.4\end{array}$ & $\begin{array}{c}\text { Chrom } \\
\log D 2.7\end{array}$ & Cpd & $\begin{array}{c}\text { Chrom } \\
\log D 7.4\end{array}$ & $\begin{array}{c}\text { Chrom } \\
\log D 2.7\end{array}$ \\
\hline 1 & 2.99 & 1.35 & 21 & 1.48 & 0.40 \\
\hline 2 & 2.71 & 1.16 & 22 & 1.07 & 0.10 \\
\hline 3 & 3.44 & 1.39 & 23 & 2.05 & 0.74 \\
\hline 4 & 3.07 & 1.39 & 24 & 1.81 & 0.57 \\
\hline 5 & 7.28 & 7.34 & 25 & 1.81 & 0.61 \\
\hline 6 & 5.11 & 7.15 & 26 & 1.44 & 0.36 \\
\hline 7 & 7.40 & 5.31 & 27 & 5.24 & 5.31 \\
\hline 8 & 7.40 & 5.31 & 28 & 2.71 & 1.29 \\
\hline 9 & 2.79 & 1.24 & 29 & 1.20 & 0.10 \\
\hline 10 & 3.03 & 1.43 & 30 & ND & ND \\
\hline 11 & 3.07 & 1.50 & 31 & 1.77 & 0.48 \\
\hline 12 & 3.93 & 2.01 & 32 & 2.75 & 2.77 \\
\hline 13 & 3.56 & 1.79 & 33 & 2.09 & 0.80 \\
\hline 14 & 2.67 & 1.16 & 34 & 2.99 & 1.43 \\
\hline 15 & ND & ND & 35 & 2.99 & 5.69 \\
\hline 16 & 3.11 & 1.37 & 36 & 2.30 & 0.99 \\
\hline 17 & 3.11 & 1.46 & 37 & 1.89 & 0.74 \\
\hline 18 & 6.99 & 7.08 & 38 & 1.24 & 0.19 \\
\hline 19 & 7.11 & 4.52 & 39 & 1.77 & 0.53 \\
\hline 20 & 7.07 & 4.50 & 40 & 1.52 & 0.40 \\
\hline
\end{tabular}

Principal component analysis of biological data and calculated structural descriptors has been done. Loading plot shows grouping of $2 \mathrm{D}$ and $3 \mathrm{D} I \mathrm{IC}_{50}$ values; grouping of lipophilicity descriptors, reflecting the consistency between calculated and experimentally obtained ones as well as clustering of basicity and polarity descriptors. Score plot, indicates that compound data points are well distributed using calculated and measured descriptors (Figure 6).

Partial least square discriminant analysis (PLS_DA) has been applied in order to build QSAR models for antiproliferative activity data. Classification approach has been selected based on the semi-quantitative nature of measured biological data. In case of MDA-MB-231 cells, 26 compounds with $\mathrm{IC}_{50}$ less than $12 \mu \mathrm{M}$ are treated as active (class 1 ) and 14 compounds with $\mathrm{IC}_{50}$ greater than 30 a $\mathrm{M}$ are treated as not active. 35 compounds were used in the training set and 5 compounds were defined as a small validation set. PLS-DA model is shown on Figure 7. 
Very good separation of two defined classes has been obtained with only 2 compounds out of 40 misclassified. It would be useful to repeat biological test for this two compounds as they are both structurally more similar to the compounds in the predicted classes. First compound is $\mathbf{4 0}$, predicted to be active and experimentally
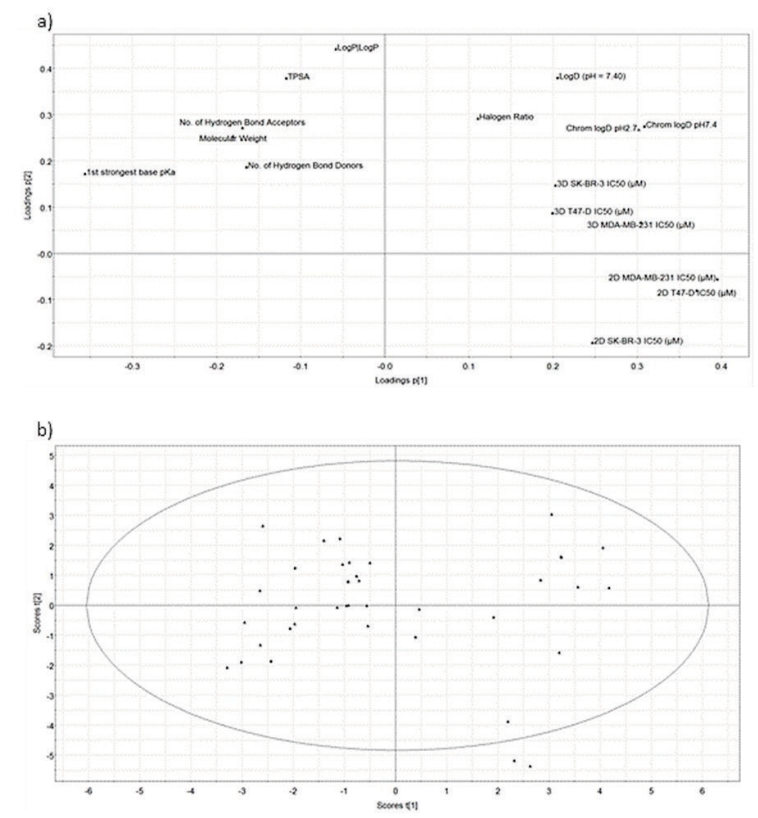

Figure 6. a) PCA loadings and b) scores of the first two components for the biological and structural data.

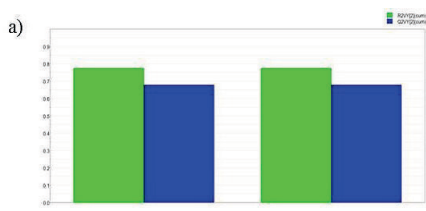

b)

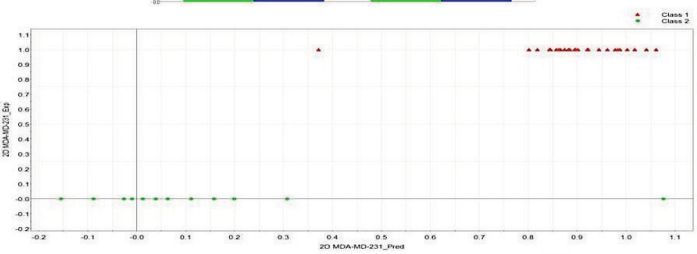

c)

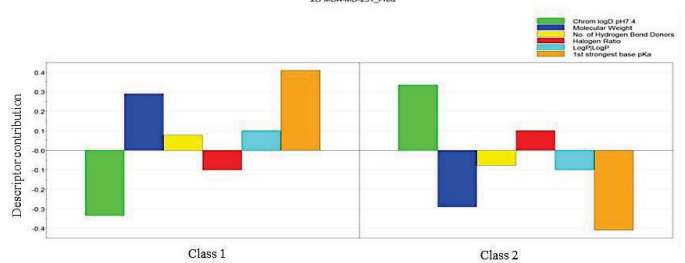

Figure 7. PLS-DA model (class1 -active, class2-in-active) for 2D MDA-MB-231 cell data: a) statistical parameters, calculated vs. b) experimental data and c) descriptor coefficients. determined to be non-active. Compound $\mathbf{4 0}$ is carrying acetamidine group which adds to activity on structurally similar compounds $\mathbf{2 5}$ and $\mathbf{2 6}$. Second compound is $\mathbf{2 8 ,}$ predicted to be non-active, experimentally being active, while its closest structural analogues are non-active. This discrepancy between calculated and experimental data might also be result of some specific target based interactions which cannot be deconvoluted from the current data set. Five compounds in the validation set, 1, 7, 31, 37 and 39, have all been properly classified; three of them being active and two non-active (Table 4).

Descriptor contributions to the PLS-DA model are shown on Figure $7 \mathrm{c}$ as coefficients to the models for Class1 and Class2. Inverse contributions are observed for these two classes, as expected. Basicity, molecular weight and number of $\mathrm{H}$-bond donors are main factors contributing to the activity of investigated compounds. These three descriptors account for a combined effect of specific interactions with biological target, presumably DNA unwinding and intercalation as discussed in section Structure-activity relationship (SAR) in 2D assays, as well as increase in permeability resulting in the activity of compound. Chrom $\log D$ and number of halogen atoms are positively related to lack of activity of compounds. This result might also be a consequence of the property distribution of the current data set and the fact that chrom $\log D$ is a combined measure of lipophilicity and ionizability of the compounds.

Since measured anti-proliferative activity is complex phenomena consisting of, at least, two major parameters; permeability and uptake into cells as well as interaction with biological target(s), larger data set is needed to deconvolute these two phenomena and to determine preferable property ranges. We showed previously on a different set of compounds that uptake into cells is mainly governed by lipophilicity and basicity of compounds. ${ }^{[31]}$

Statistical models for the 3D cells are in general somewhat less accurate with similar descriptor contribution. Weaker ability to distinguish between active and non-active compounds indicates some additional underlying features that also play important role in antiproliferative activity on the $3 \mathrm{D}$ cell, but were not used in

Table 4. Prediction values for the validation compounds.

\begin{tabular}{cccc}
\hline $\begin{array}{c}\text { Compound / } \\
\text { 2D MDA-MB-231 }\end{array}$ & $\begin{array}{c}\text { Probability } \\
\text { Pred_Class1 }\end{array}$ & $\begin{array}{c}\text { Probability } \\
\text { Pred_Class2 }\end{array}$ & $\mathrm{IC}_{50} / \mu \mathrm{M}$ \\
\hline 1 & 0.80 & 0.19 & 5.4 \\
7 & 0.03 & 0.96 & 30 \\
31 & -0.09 & 1.09 & 30 \\
37 & 0.95 & 0.04 & 3.5 \\
39 & 0.85 & 0.14 & 3.0 \\
\hline
\end{tabular}


the current study. Inverted contribution of HBDs for 3D assay in comparison with 2D assay supports assumption of different membrane permeability for 2D and 3D assays but this differential behaviour needs further investigation.

\section{CONCLUSIONS}

We compared the drug activity of 40 benzo[b]thieno, thieno[2,3-b]thiophene and thieno[3,2-b]thiophene-2carboxanilides, and [2,3-c]quinolone compounds on the three human breast cancer cell lines (SK-BR-3, MDA-MB$231, T-47 D)$ grown in 2D and 3D cell culture conditions. All three cell lines forms optimal tumor spheres 4 days after seeding of the cells in 3D culture plate. Doxorubicin, used as a standard drug, showed higher $\mathrm{IC}_{50}$ values in $3 \mathrm{D}$ cell culture format assay, in comparison with 2D, in all three cell lines. In general, 40 tested NCEs showed higher $\mathrm{IC}_{50}$ values in 3D format assay than in 2D in all three cell lines. Although biological significance of obtained data is still poorly understood, discrepancy of $I_{50}$ values illustrated importance of implementation of 3D cell culture assays in early screening cascade. Assay quality parameters ( $Z^{\prime}$ and $\mathrm{S}: \mathrm{B})$ were high and reproducible, both for $2 \mathrm{D}$ and $3 \mathrm{D}$ cell assays. For these compounds, experimental lipophilicity, as determined by RP-HPLC was expressed by using chrom $\log D$. These values were in the range $1.07-7.40$ at $\mathrm{pH} 7.4$ and between $0.10-7.34$ at $\mathrm{pH}$ 2.7. Physico-chemical properties of investigated compounds have been studied in terms of lipophilicity expressed as chrom $\log D$ values and calculated structural parameters: number of hydrogen bond donors and acceptors, calculated $\log P$ and $\log D$ values, molecular weight, ionization constants $\left(\mathrm{p} K_{\mathrm{a}}\right)$. PLSDA model has been developed with good classification power, distinguishing active from non-active compounds in 2D assay. Basicity, molecular weight and number of $\mathrm{H}$-bond donors are main factors contributing to the antiproliferative effect of investigated compounds. Simple structural and physico-chemical parameters identified in the current study can be used as a useful tool, in the early phases of the research, to design, filter and prioritize compounds for synthesis and screening for antiproliferative activity. They can also serve as a sound basis for further, more detailed investigation of differential activity in 2D and 3D cells.

To prove scientific relevance of compound activities obtained in 3D cell cancer cell lines in vitro it is necessary to tested active compounds in animal cancer models.

Acknowledgment. This study was funded by the Croatian Ministry of Science Education and Sports under the project 125-0982464-1356, Croatian Science Foundation under the project 5596 and Fidelta Ltd.

\section{REFERENCES}

[1] J. Bin Kim, Semin. Cancer Biol. 2005, 15, 365.

[2] A. Abbott, Nature 2003, 424, 870.

[3] S. Breslin, L. O'Driscoll, Drug Discov. Today 2013, 18, 240.

[4] O. Zschenker, T. Streichert, S. Hehlgans, N. Cordes, PLoS One 2012, 7, e34279.

[5] K. L. Schmeichel, M. J. Bissell, J. Cell Sci. 2003, 116, 2377.

[6] Y.-C. Tung, A. Y. Hsiao, S. G. Allen, Y. Torisawa, M. Ho, S. Takayama, Analyst 2011, 136, 473.

[7] K. Brajša, I. Vujasinović, D. Jelić, M. Trzun, I. Zlatar, G. Karminski-Zamola, M. Hranjec, J. Enzyme Inhib. Med. Chem. 2015, 6366, 1.

[8] A. I. Minchinton, I. F. Tannock, Nat. Rev. Cancer 2006, 6, 583.

[9] R. B. Silverman, The Organic Chemistry of Drug Design and Drug Action, Elsevier Academic Press, 2004.

[10] B. Letafat, S. Emami, N. Mohammadhosseini, M. A. Faramarzi, N. Samadi, A. Shafiee, A. Foroumadi, Chem. Pharm. Bull. (Tokyo) 2007, 55, 894.

[11] S.-W. Wang, S.-L. Pan, Y.-C. Huang, J.-H. Guh, P.-C. Chiang, D.-Y. Huang, S.-C. Kuo, K.-H. Lee, C.-M. Teng, Mol. Cancer Ther. 2008, 7, 350.

[12] J. Dogan Koruznjak, M. Grdisa, N. Slade, B. Zamola, K. Pavelić, G. Karminski-Zamola, J. Med. Chem. 2003, 46, 4516.

[13] K. Ester, M. Hranjec, I. Piantanida, I. Caleta, I. Jarak, K. Pavelić, M. Kralj, G. Karminski-Zamola, J. Med. Chem. 2009, 52, 2482.

[14] I. Jarak, M. Kralj, L. Suman, G. Pavlović, J. Dogan, I. Piantanida, M. Zinić, K. Pavelić, G. Karminski-Zamola, J. Med. Chem. 2005, 48, 2346.

[15] I. Jarak, M. Kralj, I. Piantanida, L. Šuman, M. Žinić, K. Pavelić, G. Karminski-Zamola, Bioorganic Med. Chem. 2006, 14, 2859.

[16] M. Aleksić, B. Bertoša, R. Nhili, L. Uzelac, I. Jarak, S. Depauw, M. H. David-Cordonnier, M. Kralj, S. Tomić, G. Karminski-Zamola, J. Med. Chem. 2012, 55, 5044.

[17] M. Aleksić, B. Bertoša, R. Nhili, S. Depauw, I. MartinKleiner, M.-H. David-Cordonnier, S. Tomić, M. Kralj, G. Karminski-Zamola, Eur. J. Med. Chem. 2014, 71, 267.

[18] R. Lama, L. Zhang, J. M. Naim, J. Williams, A. Zhou, B. Su, Bioorg. Med. Chem. 2013, 21, 922.

[19] M. Maliepaard, N. J. de Mol, L. H. Janssen, W. van der Neut, W. Verboom, D. N. Reinhoudt, Anticancer. Drug Des. 1992, 7, 415.

[20] M. J. McKeage, S. J. Berners-Price, P. Galettis, R. J. Bowen, W. Brouwer, L. Ding, L. Zhuang, B. C. Baguley, Cancer Chemother. Pharmacol. 2000, 46, 343. 
[21] M. Bajda, S. Boryczka, J. Wietrzyk, B. Malawska, Biomed. Chromatogr. 2007, 21, 123.

[22] R. J. Young, D. V. S. Green, C. N. Luscombe, A. P. Hill, Drug Discov. Today 2011, 16, 822.

[23] K. Valkó, C. Bevan, D. Reynolds, Anal. Chem. 1997, 69, 2022.

[24] K. Valkó, Wiley, Holboken, NJ, 2014, p. 450.

[25] K. Valkó, P. Slégel, J. Chromatogr. A 1993, 631, 49.

[26] M. Cindrić, S. Jambon, A. Harej, S. Depauw, M.-H. David-Cordonnier, S. Kraljević Pavelić, G. KarminskiZamola, M. Hranjec, Eur. J. Med. Chem. 2017, 136, 468.

[27] S. Réjiba, C. Bigand, C. Parmentier, A. Hajri, Neoplasia 2009, 11, 637.
[28] C. P. Coyne, T. Jones, R. Bear, Med. Chem. (Los. Angeles). 2013, 3, 210.

[29] N. Awasthi, C. Zhang, A. M. Schwarz, S. Hinz, C. Wang, N. S. Williams, M. A. Schwarz, R. E. Schwarz, Carcinogenesis 2013, 34, 2361.

[30] T. J. Cheeseright, M. Holm, F. Lehmann, S. Luik, M. Gottert, J. L. Melville, S. Laufer, J. Med. Chem. 2009, 52,4200 .

[31] V. Stepanić, S. Koštrun, I. Malnar, M. Hlevnjak, K. Butković, I. Ćaleta, M. Dukši, G. Kragol, O. MakaruhaStegić, L. Mikac, J. Ralić, I. Tatić, B. Tavčar, K. Valko, S. Zulfikari, V. Munić, J. Med. Chem. 2011, 54, 719.

[32] K. Brajša, M. Trzun, I. Zlatar, D. Jelić, Period. Biol. 2016, 118, 59. 